\title{
Analysis on Topology of Grounding System Using Bentonite and Coconut Husk as Additive Material
}

\author{
N H Halim, 1,* M F Hairuddin², S N M Arshad ${ }^{3}$, M Isa ${ }^{3}$, Z Adzis ${ }^{3}$, A W Y Khang ${ }^{3}$ \\ ${ }^{1}$ Centre of Excellence for Renewable Energy (CERE), School of Electrical System Engineering, Pauh Putra Main Campus, Universiti \\ Malaysia Perlis, Perlis, Malaysia \\ ${ }^{2}$ Institute of High Voltage and High Current (IVAT), School of Electrical Engineering, Faculty of Engineering, Universiti Teknologi \\ Malaysia, Malaysia \\ ${ }^{3}$ Faculty of Electrical and Electronic Engineering Technology, Kampus Teknologi, Universiti Teknikal Malaysia Melaka, Hang Tuah \\ Jaya, Melaka, Malaysia
}

Received August 14, 2019; Revised December 18, 2019; Accepted December 24, 2019

Copyright $\bigcirc 2019$ by authors, all rights reserved. Authors agree that this article remains permanently open access under the terms of the Creative Commons Attribution License 4.0 International License

\begin{abstract}
Electrical grounding is a system to remove undesired electrical charge to the ground via grounding mass. The unwanted electrical charged maybe created due to grounding fault of electrical apparatus and transient. Without proper grounding system, any structure will have exposed to the risk that caused by fault current and lightning. This situation will contribute to the loss of life and damaging the equipment. The purpose of this research is to investigate the behavior of bentonite and coconut husk as additive material to improve the performance grounding system by reducing grounding resistance value. At the same time, the proposed grounding system is also installed in two different topologies which are the single driven rod as the first topology and the radial multiple driven rod as the second topology instead of the conventional method that installing multiple rod in straight line. After the installation process is completed, the measurement of grounding resistance work was conducted using fall of potential method and recorded within 64 days. The data gained then was compared and analyzed to identify the best material to be used as the grounding enhancement or additive material. The results obtained show that the Bentonite has better performance than coconut husk in reducing grounding resistance. This research also found that the new configuration of multiple driven rod topology was able to reduce grounding resistance compared to the single driven rod.
\end{abstract}

Keywords Grounding, Additive Material, Bentonite, Coconut Husk

\section{Introduction}

Grounding in electrical engineering field means the process of connecting any electrically part to the mother earth of which the potential is treated as the zero reference. This is very important part in the fields of lightning protection, power, and communication system. In lightning protection system, the grounding acts as the interface between natural transient phenomena from cloud (lightning) and the masses of soil. The purpose of the grounding system is to divert the flow of charge to the soil masses as fast as possible. This paper addresses the research finding of grounding systems used in lightning protection methodologies. Energy is transferred at a frequency of 50 $\mathrm{Hz}$ in power system while in lightning phenomena energy is distributed in a large spectrum that peaks at the $\mathrm{kHz}$ range [1, 2]. A lightning protection system consists of three main parts which are air-termination, down conductors and grounding system. Air termination system functioned to interceptthe downward stepped leader followed by down conductor which brings the lightning current to the base of the structures and grounding system then disperses lightning energy into earth as fast as possible [3].

The improvement of grounding system can be achieved by reducing the resistance that exists between grounding electrode and the soil as lower as possible. There are several ways that can be applied to reduce the grounding electrode resistance. The first method is increasing the length electrode in the ground. Theoretically, driving a longer rod deeper into the ground, materially decreasing its resistance. In general, doubling the rod length reduces resistance by about 40 percent. The other approaches are by increasing the diameter of grounding electrode. The resistance will decrease, but only a little. For the same depth, doubling the electrode diameter reduces the resistance only about 10 percent. The second method to improve grounding system is by using the multiple rod of grounding electrode. When two well-spaced rods driven 
into the ground they will provide parallel paths. The analogy of this situation can be represented as two resistances connecting in parallel. But in grounding system the rule for two resistances in parallel does not apply exactly. The equivalent resistance is not one-half of the individual grounding electrode resistances (assuming all electrodes have the same size and depth). Actually, the reduction for two equal resistance rods is about 40 percent. If three rods are used, the reduction is 60 percent, if four, 66 percent [4].

Soil treatment with enhancement material is a good way to reduce the grounding resistance when the grounding electrode cannot be driven deeper because of some factors such as hard underlying rock. In this research, the soil is treated in order to improve the performance of the grounding system, with single and some grounding electrode installed vertically in the soil. Two types of enhancement material can be used for soil treatment which are chemical enhancement material (CEM) and natural enhancement material (NEM). The enhancement material will reduce the soil resistivity as the materials could help in increasing the soil ability to absorb the moisture from the surrounding soil and be able to retain the moisture within its structure [5].

\section{Materials and Methodology}

This research using driven rod method for grounding system installation purpose. In this experiment the materials used are copper conductor as the grounding electrodes while coconut husk and bentonite are used as the additive material. The size of the proposed grounding system is scaled down with length of the electrodes used is $0.5 \mathrm{~m}$ in length comprising eighteen electrodes for two experimental sites. The cylindrical pit is employed to put both additive material and grounding electrode with dimension of $0.1016 \mathrm{~m}$ wide and $0.5 \mathrm{~m}$ long. Figure 1 shows the side view grounding pit model. The copper conductor/rod is used as the grounding electrodes while coconut husk and bentonite are used as the additive material. The size of the proposed grounding system is scaled down with length of the electrodes used being $0.5 \mathrm{~m}$ in length comprising eighteen electrodes for two experimental sites. The cylindrical pit is employed to put both additive material and grounding electrode with dimension of $0.1016 \mathrm{~m}$ wide and $0.5 \mathrm{~m}$ long. Figure 1 shows the side view grounding pit model.

Bentonite is a type of mineral formed through devitrification of vitreous volcanic ash. This material in powder form in dry condition and in natural clays in wet condition with a high water absorption capacity causes it to expand and swell. Bentonite density in dry condition varies depending on the quality, and may range from 2.2 to 2.8 $\mathrm{g} / \mathrm{cm}^{3}$. Coconut husk is the result of wasted material from coconut fruit. Most of the coconut is found on the coast and there are many in Asia. The use of coconut fruit is coconut milk as a flavour enhancer in cooking. The result of coconut waste can be used as a source for producing electricity by means of biomass generation. Therefore, coconut husks are used in experiments as a material that reduces soil resistance on the chosen area.

Grounding system is very important in the protection system. The choice of a conductor should take some consideration such as conductivity, resistance due to corrosion and strength. Additionally, the conductor used should have good reliability for a long time usage but not too expensive. Copper electrode is fulfilling the above mentioned characteristic. Using galvanized steel as grounding rod is better than copper, because the galvanized steel resistance is lower than copper, so the performance of the grounding system will be better. Regarding to the study that was conducted by Hazrek Hamzah, [6] proved that the grounding resistance of galvanized steel grounding system is lower than the copper grounding system. But according to Raj Singh [7], 10 mil copper bonded steel rods are acceptable for a service life up to 40 years and for a galvanized rod with 3.9 mils of zinc being expected to provide for 10-15 years of a lifetime from corrosion. This finding shows that copper electrode is widely used in grounding system in the world regarding to their long lifetime compared to other materials although it is a little bit expensive [8]. By considering all the aforementioned factors, the site chosen for installation and measurement of grounding system is located at a plot of vacant land near the mosque of the Universiti Malaysia Perlis (UniMAP) main campus as shown in Figure 2. This land area consists of hilly soil that may influence the performance of the soil. So, the moisture content, salinity and also compactness of the soil will vary the level of soil resistivity. If the moisture, salinity, and compactness of soil are low, the soil resistivity will be high.

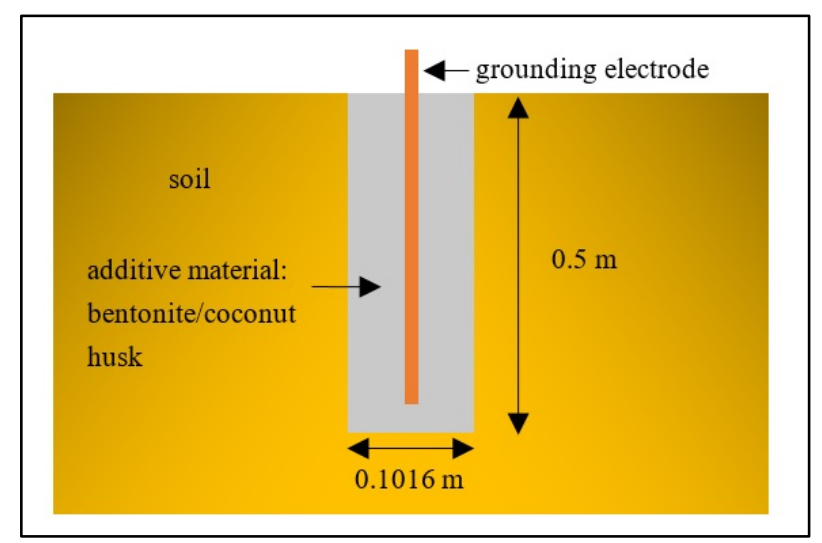

Figure 1. Side view of grounding pit with additive material and electrode 


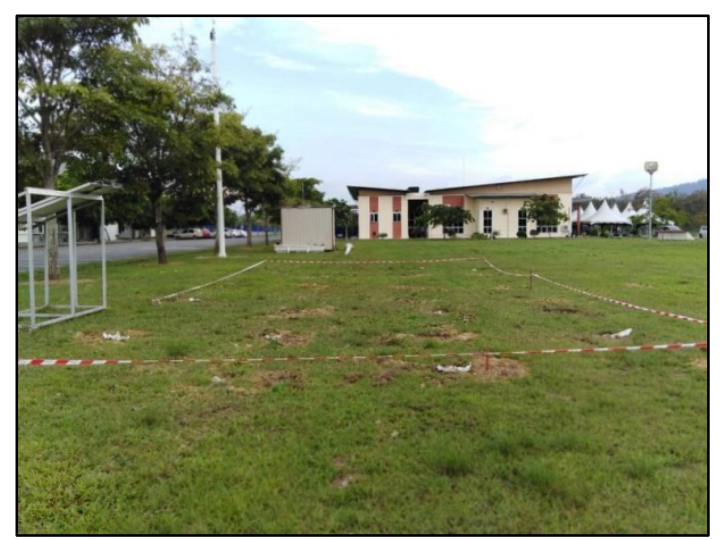

Figure 2. Grounding system installation site

The conventional method using multiple rod in straight line to decrease the grounding resistance. This research proposed new topology with all electrodes were arranged in radial multiple driven rod form. The arrangement of all electrodes regarding to the proposed topology is shown in Figure 3. Since this study used two different additive materials the grounding electrodes installation is also divided into two sites. Each site consists 9-unit copper electrodes where the reference or main electrode is located at the centre and the rest are located at the outer site. This work applied Fall Potential Method (3-pin method) to measure grounding resistance of grounding system installed as shown in Figure 4. In this method current, $I$ is injected into the earth using a current probe. The potential probe which is inserted at intervals within the current path will measure the voltage drop, $V$ produced by the current. The form of fall of the potential method is obtained when the grounding electrode, potential probe, and current probe are on a straight line and the potential probe is located between the grounding electrode and a current probe [9]. The measurement was conducted five times for each site with the first time measurement only involving the reference electrode without connected to the other electrodes.

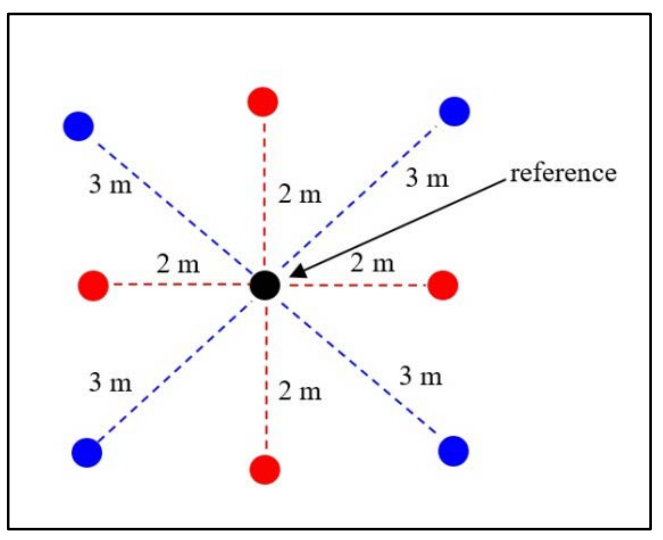

Figure 3. Grounding electrodes arrangement

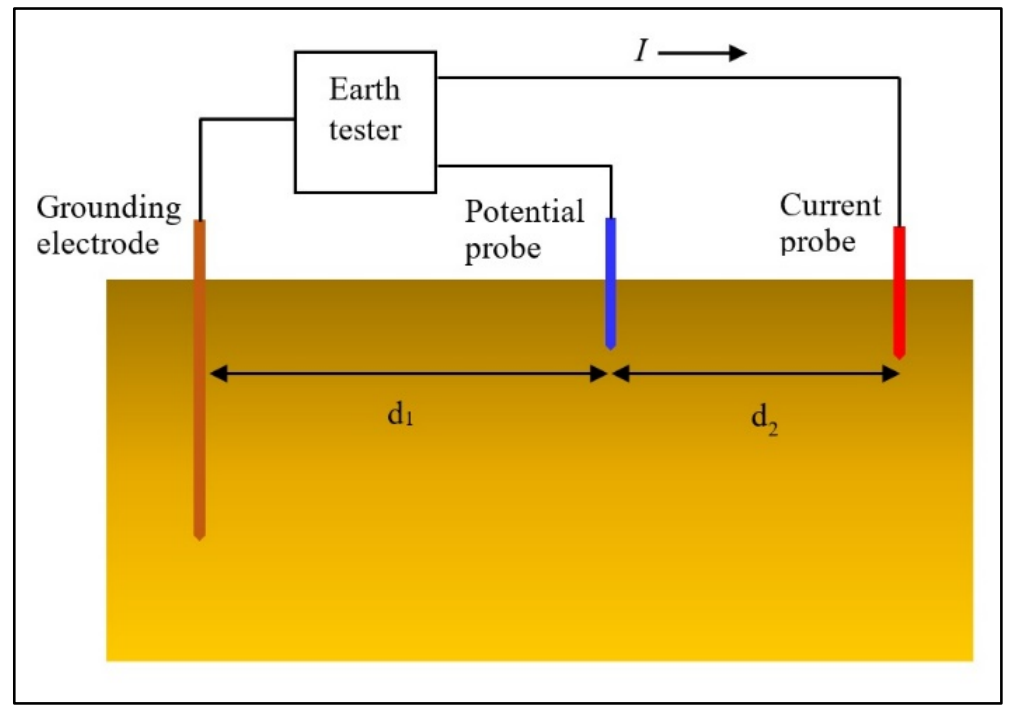

Figure 4. Grounding resistance measurements using fall of potential method 
The equation of grounding resistance, $R$ is given by the following equation:

$$
R=\frac{\rho}{2 \pi l}\left(\ln \left(\frac{4 l}{r}\right)-1\right)
$$

Where:

$\mathrm{R}=$ grounding resistance $(\Omega)$

$\rho=$ soil resistivity $(\Omega-m)$

$\mathrm{l}=$ length of electrode $(\mathrm{m})$

$\mathrm{r}=$ radius of electrode $(\mathrm{m})$

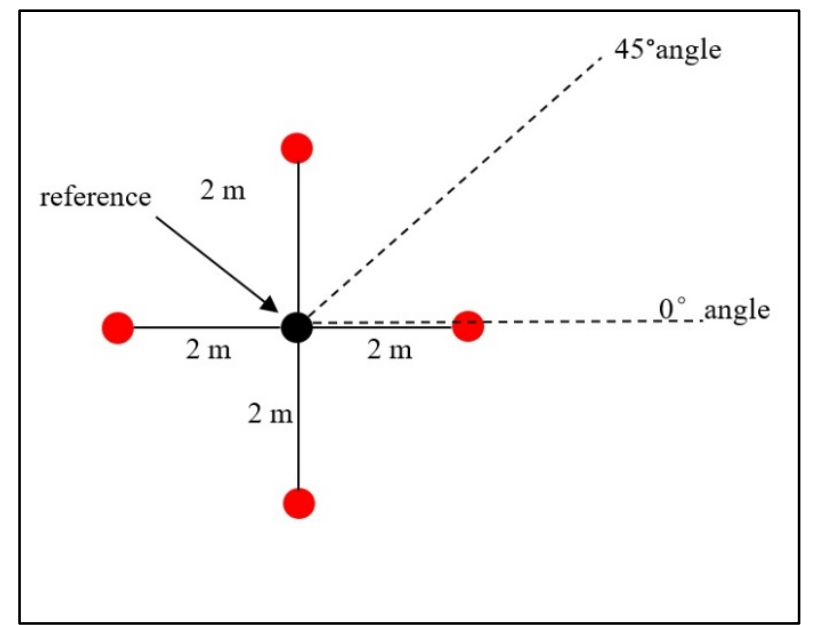

Figure 5. Radial Multiple driven rod topology with $2 \mathrm{~m}$ spacing of outer electrode

The second time measurement then conducted with all four outer electrodes with the spacing of $2 \mathrm{~m}$ connected to the reference electrode as shown in Figure 5 with the angle of both potential and current probe from the reference electrode is set to $0^{\circ}$. The third time measurement done with the same spacing but the angle was changed to $45^{\circ}$. The fourth and fifth time measurements repeating the same step as the second and third time measurement but only all outer electrodes with spacing of $3 \mathrm{~m}$ connected to the reference electrode. The grounding resistance, $R$ of multiple driven rod is given by the following formula:

$$
R=\frac{1}{n} \frac{\rho}{2 \pi l}\left(\ln \frac{8 l}{d}-1+\frac{l}{a} \ln \left(\frac{1.78 n}{2.718}\right)\right)
$$

Where:

$\mathrm{R}=$ grounding resistance $(\Omega)$

$\rho=$ soil resistivity $(\Omega-\mathrm{m})$

$\mathrm{l}=$ length of electrode $(\mathrm{m})$

$\mathrm{a}=$ spacing between electrode $(\mathrm{m})$

$\mathrm{d}=$ diameter of electrode $(\mathrm{m})$

$\mathrm{n}=$ number of electrodes

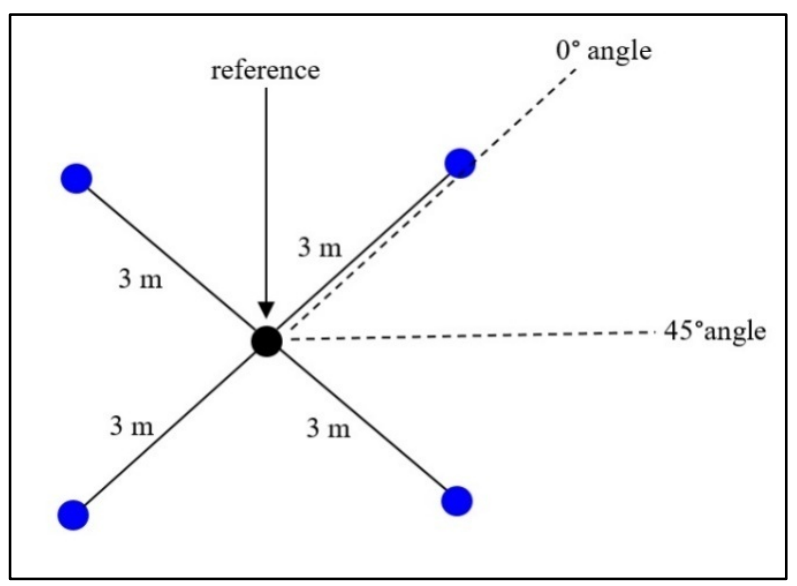

Figure 6. Radial multiple driven rod topology with $3 \mathrm{~m}$ spacing of outer electrode

\section{Results and Discussions}

The grounding resistance measurement has been carried out within 64 days from January 2019 to March 2019. The arrangement of measurement was divided to five which are single driven rod, radial multiple driven rod (2 $\mathrm{m}$ for 0 ), radial multiple driven rod ( $2 \mathrm{~m}$ for 45$)$, radial multiple driven rod ( $3 \mathrm{~m}$ for 0 ) and radial multiple driven rod ( $3 \mathrm{~m}$ for 45). There is some comparison that has been made to analyse the performance two different additive material on designed grounding pit regarding to the topology. The measurement data of grounding pit with bentonite were recorded and tabulated in Table 1 while the pit with coconut husk in Table 2. 
Table 1. Grounding Resistance on Bentonite Pit

\begin{tabular}{|c|c|c|c|c|c|c|c|c|c|c|c|}
\hline \multirow[b]{2}{*}{ Day } & \multirow{2}{*}{$\begin{array}{c}\text { Single } \\
\text { Driven Rod } \\
(\Omega)\end{array}$} & \multicolumn{4}{|c|}{ Radial Multiple Driven Rod Topology } & \multirow[b]{2}{*}{ Day } & \multirow{2}{*}{$\begin{array}{c}\text { Single } \\
\text { Driven Rod } \\
(\Omega)\end{array}$} & \multicolumn{4}{|c|}{ Radial Multiple Driven Rod Topology } \\
\hline & & $\begin{array}{c}2 \mathrm{~m} \text { on } \\
0^{\circ} \\
(\Omega)\end{array}$ & $\begin{array}{c}2 \mathrm{~m} \text { on } \\
45^{\circ} \\
(\Omega)\end{array}$ & $\begin{array}{c}3 \mathrm{~m} \\
\text { on } 0^{\circ} \\
(\Omega)\end{array}$ & $\begin{array}{c}3 \mathrm{~m} \text { on } \\
45^{\circ} \\
(\Omega)\end{array}$ & & & $\begin{array}{c}2 \mathrm{~m} \text { on } 0^{\circ} \\
(\Omega)\end{array}$ & $\begin{array}{c}2 \mathrm{~m} \text { on } \\
45^{\circ} \\
(\Omega)\end{array}$ & $\begin{array}{c}3 \mathrm{~m} \\
\text { on } 0^{\circ} \\
(\Omega)\end{array}$ & $\begin{array}{c}3 \mathrm{~m} \text { on } \\
45^{\circ} \\
(\Omega)\end{array}$ \\
\hline 1 & 28.5 & 14.4 & 12.1 & 10.1 & 7.8 & 33 & 62.4 & 23.1 & 22.5 & 17.4 & 17.4 \\
\hline 2 & 42.5 & 25.1 & 23.9 & 11.1 & 10.7 & 34 & 72.1 & 28.5 & 28.2 & 26.6 & 25.6 \\
\hline 3 & 26.5 & 11.7 & 10.5 & 15.4 & 11.7 & 35 & 65.2 & 24.2 & 22.8 & 17.7 & 16.8 \\
\hline 4 & 26.3 & 15.8 & 15.3 & 13.3 & 10.1 & 36 & 79.5 & 35.4 & 34.2 & 33.4 & 32.5 \\
\hline 5 & 26.7 & 21.3 & 21.2 & 14.5 & 13.7 & 37 & 89.4 & 50.6 & 50.1 & 45.2 & 45 \\
\hline 6 & 27.2 & 26 & 25 & 16.3 & 16.7 & 38 & 90.4 & 33.4 & 32.5 & 26.5 & 25.5 \\
\hline 7 & 28.1 & 14.5 & 14.4 & 11.4 & 11.2 & 39 & 156.3 & 39.6 & 39.1 & 22.4 & 21.2 \\
\hline 8 & 28.5 & 22.5 & 21.4 & 13.4 & 12.6 & 40 & 162.2 & 54.3 & 54.2 & 33.4 & 32.1 \\
\hline 9 & 27.6 & 22.2 & 21.5 & 13.4 & 12.7 & 41 & 29.3 & 8.3 & 8.2 & 6.5 & 6.4 \\
\hline 10 & 31.4 & 22.5 & 22.4 & 15.5 & 14.4 & 42 & 29.9 & 13.3 & 11 & 10.4 & 7.1 \\
\hline 11 & 32.6 & 13.9 & 13.8 & 11.9 & 12 & 43 & 31 & 22 & 21.3 & 11 & 10 \\
\hline 12 & 38.9 & 33.9 & 33.7 & 12.4 & 12.1 & 44 & 32.7 & 12.2 & 12 & 10.8 & 10.4 \\
\hline 13 & 34.7 & 20.2 & 20.1 & 13.3 & 13 & 45 & 35.1 & 15.6 & 14.8 & 14.1 & 13.9 \\
\hline 14 & 36.7 & 15.5 & 15.4 & 14.9 & 13.7 & 46 & 39.9 & 31.5 & 21.3 & 17.5 & 13.1 \\
\hline 15 & 37.7 & 16.2 & 15 & 14 & 14.1 & 47 & 45.2 & 23.9 & 23.7 & 16.6 & 13.9 \\
\hline 16 & 36.6 & 17.2 & 15.4 & 14.8 & 15.01 & 48 & 54.7 & 18.6 & 15.7 & 30.5 & 23.6 \\
\hline 17 & 35.4 & 16.8 & 14.9 & 15.1 & 14.08 & 49 & 56.9 & 18.9 & 17.8 & 31.4 & 24.7 \\
\hline 18 & 45 & 17.7 & 17.6 & 14.2 & 13.9 & 50 & 61.7 & 30.5 & 30.4 & 24.1 & 20.3 \\
\hline 19 & 54 & 29.9 & 29.8 & 23.6 & 23.5 & 51 & 69.45 & 23.8 & 22.3 & 22.3 & 24.3 \\
\hline 20 & 56.3 & 27.9 & 27.3 & 15.3 & 15.5 & 52 & 65.3 & 27.4 & 23.9 & 21.8 & 28.9 \\
\hline 21 & 58.4 & 18.2 & 17.7 & 22 & 21.8 & 53 & 86 & 64.5 & 61.4 & 30.2 & 30.1 \\
\hline 22 & 62.5 & 23.7 & 23.5 & 17.6 & 17.2 & 54 & 97 & 53.8 & 53.3 & 50 & 32.6 \\
\hline 23 & 64.5 & 24.7 & 24.5 & 17.6 & 16.9 & 55 & 99.9 & 55.4 & 54.7 & 36 & 35.6 \\
\hline 24 & 64.1 & 23.5 & 23.2 & 17.7 & 16.8 & 56 & 51.8 & 24.3 & 23.8 & 15 & 14.7 \\
\hline 25 & 62.1 & 23.2 & 22.5 & 16.8 & 16.6 & 57 & 54 & 29.9 & 29.8 & 23.6 & 23.5 \\
\hline 26 & 61.2 & 24.1 & 23.1 & 17.5 & 16.7 & 58 & 29.9 & 13.3 & 11 & 10.4 & 7.1 \\
\hline 27 & 62.1 & 23.2 & 21.2 & 17.6 & 15.8 & 59 & 31 & 22 & 21.3 & 11 & 10 \\
\hline 28 & 90.4 & 50.6 & 50.1 & 45.2 & 45 & 60 & 32.7 & 21.3 & 20.8 & 14.52 & 14.5 \\
\hline 29 & 78.2 & 35.4 & 34.2 & 33.4 & 32.5 & 61 & 34 & 13.45 & 13.72 & 12.06 & 12.03 \\
\hline 30 & 71.3 & 27.5 & 26.4 & 26.5 & 25.5 & 62 & 36 & 17.15 & 17.22 & 13.09 & 12.81 \\
\hline 31 & 70.5 & 24.8 & 24.7 & 24.4 & 23.8 & 63 & 45 & 15.4 & 14.7 & 14.1 & 14.09 \\
\hline 32 & 63.5 & 24.2 & 22.7 & 18.6 & 17.3 & 64 & 42.5 & 20.3 & 20.2 & 13.1 & 12.9 \\
\hline
\end{tabular}


Table 2. Grounding Resistance on Coconut Husk Pit

\begin{tabular}{|c|c|c|c|c|c|c|c|c|c|c|c|}
\hline \multirow[b]{2}{*}{ Day } & \multirow[b]{2}{*}{$\begin{array}{c}\text { Single } \\
\text { Driven Rod } \\
(\Omega)\end{array}$} & \multicolumn{4}{|c|}{ Radial Multiple Driven Rod Topology } & \multirow[b]{2}{*}{ Day } & \multirow[b]{2}{*}{$\begin{array}{c}\text { Single } \\
\text { Driven Rod } \\
(\Omega)\end{array}$} & \multicolumn{4}{|c|}{ Radial Multiple Driven Rod Topology } \\
\hline & & $\begin{array}{c}2 \mathrm{~m} \text { on } \\
0^{\circ} \\
(\Omega) \\
\end{array}$ & $\begin{array}{c}2 \mathrm{~m} \text { on } \\
45^{\circ} \\
(\Omega) \\
\end{array}$ & $\begin{array}{c}\mathrm{m} \\
\text { on } 0^{\circ} \\
(\Omega) \\
\end{array}$ & $\begin{array}{c}3 \mathrm{~m} \text { on } \\
45^{\circ} \\
(\Omega) \\
\end{array}$ & & & $\begin{array}{c}2 \mathrm{~m} \text { on } 0^{\circ} \\
(\Omega)\end{array}$ & $\begin{array}{c}2 \mathrm{~m} \text { on } \\
45^{\circ} \\
(\Omega) \\
\end{array}$ & $\begin{array}{c}\mathrm{m} \\
\text { on } 0^{\circ} \\
(\Omega) \\
\end{array}$ & $\begin{array}{c}3 \mathrm{~m} \text { on } \\
45^{\circ} \\
(\Omega) \\
\end{array}$ \\
\hline 1 & 32.1 & 13.1 & 15.2 & 22 & 16.7 & 33 & 181.2 & 72.1 & 70.1 & 25.5 & 25.2 \\
\hline 2 & 31.6 & 8.2 & 8 & 7 & 6.7 & 34 & 185.1 & 75.1 & 74.1 & 30.9 & 30.8 \\
\hline 3 & 31.1 & 8.7 & 7.9 & 6.8 & 6.9 & 35 & 186.5 & 82 & 80.2 & 30.7 & 30.6 \\
\hline 4 & 43.3 & 17.2 & 11.2 & 11.8 & 11.5 & 36 & 179.2 & 81.2 & 81.1 & 31.5 & 30.2 \\
\hline 5 & 48.8 & 12.3 & 9.4 & 12.5 & 12.2 & 37 & 173.6 & 77.4 & 77.2 & 30.3 & 30.2 \\
\hline 6 & 50.1 & 17.1 & 16.7 & 10.4 & 10.3 & 38 & 180.2 & 80.1 & 71 & 31.6 & 31.5 \\
\hline 7 & 63.3 & 15.3 & 10.5 & 15.3 & 10.9 & 39 & 184.5 & 83.4 & 83 & 80.7 & 80.4 \\
\hline 8 & 70.7 & 20.1 & 19.8 & 11.4 & 11.3 & 40 & 185.1 & 85.3 & 84.9 & 82.7 & 82.3 \\
\hline 9 & 58.6 & 17.5 & 12.7 & 11 & 10.9 & 41 & 50.7 & 10.7 & 10.6 & 9.6 & 9.4 \\
\hline 10 & 58.7 & 13.2 & 13.1 & 11.4 & 10.6 & 42 & 56.5 & 11.2 & 11.1 & 10.3 & 10 \\
\hline 11 & 98 & 29.8 & 29.7 & 16.7 & 16.6 & 43 & 83.4 & 14.2 & 14.1 & 12.5 & 12.2 \\
\hline 12 & 150.3 & 22.6 & 22 & 17.3 & 17.2 & 44 & 118.7 & 17.3 & 16.9 & 14.9 & 14.4 \\
\hline 13 & 150.3 & 38.6 & 38 & 17.8 & 17.8 & 45 & 98.4 & 29.8 & 29.7 & 16.7 & 16.6 \\
\hline 14 & 171.1 & 44.6 & 44.1 & 22.5 & 20.2 & 46 & 180.7 & 22.3 & 22.2 & 18.9 & 18.5 \\
\hline 15 & 167 & 44.5 & 41.7 & 20.5 & 19.1 & 47 & 247 & 25.6 & 25.4 & 21.5 & 21.1 \\
\hline 16 & 163 & 44.5 & 44.7 & 20.8 & 19.5 & 48 & 275.8 & 27.7 & 23.6 & 24.7 & 23.1 \\
\hline 17 & 169 & 43.5 & 43.4 & 27.6 & 17.4 & 49 & 310.4 & 29.1 & 27.8 & 27.6 & 26.2 \\
\hline 18 & 185.2 & 55.6 & 34.5 & 27 & 26 & 50 & 357 & 34 & 33.8 & 29 & 29 \\
\hline 19 & 196 & 61.5 & 60.5 & 28.6 & 28.5 & 51 & 416 & 41.6 & 41.3 & 32.1 & 31 \\
\hline 20 & 178 & 67.9 & 67.7 & 35.5 & 30.4 & 52 & 435 & 43.8 & 42.7 & 32.8 & 33 \\
\hline 21 & 180 & 82.2 & 82.1 & 32.5 & 32.4 & 53 & 501 & 81 & 72 & 42.2 & 42 \\
\hline 22 & 180 & 82.2 & 82.1 & 32.5 & 32.4 & 54 & 567 & 60 & 58.1 & 49 & 48 \\
\hline 23 & 182.1 & 82 & 80.2 & 31.5 & 30.2 & 55 & 498 & 89 & 84.7 & 47.3 & 46 \\
\hline 24 & 181.2 & 81 & 79.2 & 32.1 & 30.4 & 56 & 196 & 61.5 & 60.5 & 28.6 & 29 \\
\hline 25 & 180.1 & 80.2 & 80.1 & 30.7 & 30.6 & 57 & 187 & 69.2 & 69.1 & 28.4 & 28 \\
\hline 26 & 181.5 & 80.2 & 72.1 & 32.4 & 31.5 & 58 & 56.9 & 14.2 & 14.1 & 12.5 & 12 \\
\hline 27 & 185.1 & 81.5 & 76.4 & 31.2 & 29.5 & 59 & 63.5 & 43.4 & 43.1 & 25.6 & 26 \\
\hline 28 & 186.1 & 79.1 & 70.5 & 49 & 48 & 60 & 74 & 21.3 & 21.1 & 17.3 & 17 \\
\hline 29 & 185 & 76.1 & 75.5 & 33.1 & 32 & 61 & 98.2 & 21.4 & 20.4 & 14.04 & 14 \\
\hline 30 & 185.1 & 75.1 & 74.1 & 30.9 & 30.8 & 62 & 114.4 & 17.5 & 17.4 & 15.08 & 15 \\
\hline 31 & 184.5 & 72.1 & 71.5 & 27.6 & 25.1 & 63 & 156.2 & 25.8 & 25.5 & 17.59 & 17 \\
\hline 32 & 180.1 & 74 & 72.1 & 26.1 & 25 & 64 & 151.4 & 33 & 32.5 & 17.5 & 17 \\
\hline
\end{tabular}

The performance grounding system with Bentonite as additive material is presented graphically in Figure 7. On the beginning, grounding resistance of all topologies starts on low value before going to increase time by time beyond the day 26. The trends of resistance go to decrease after that and reach to the peak value on day 40 . The highest grounding resistance recorded on single driven rod with the resistance up to $162 \Omega$. However, the resistance dropped drastically on day 41 before slowly increasing onward. The lowest resistance is achieved on radial multiple driven rod star topology with $3 \mathrm{~m}$ spacing between reference and outer electrode which is grounding resistance of $6.4 \Omega$. 


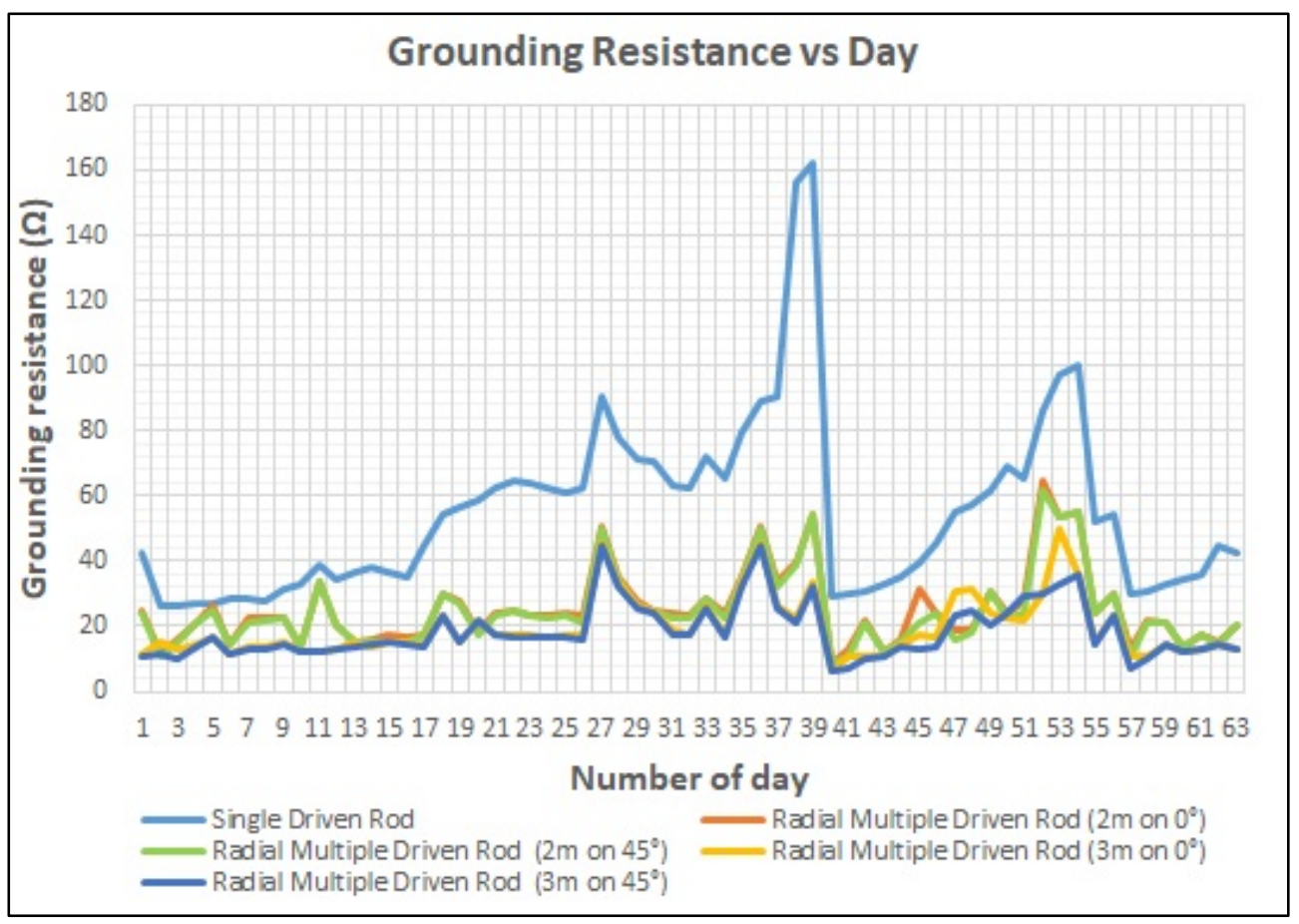

Figure 7. Grounding resistance of bentonite grounding pit

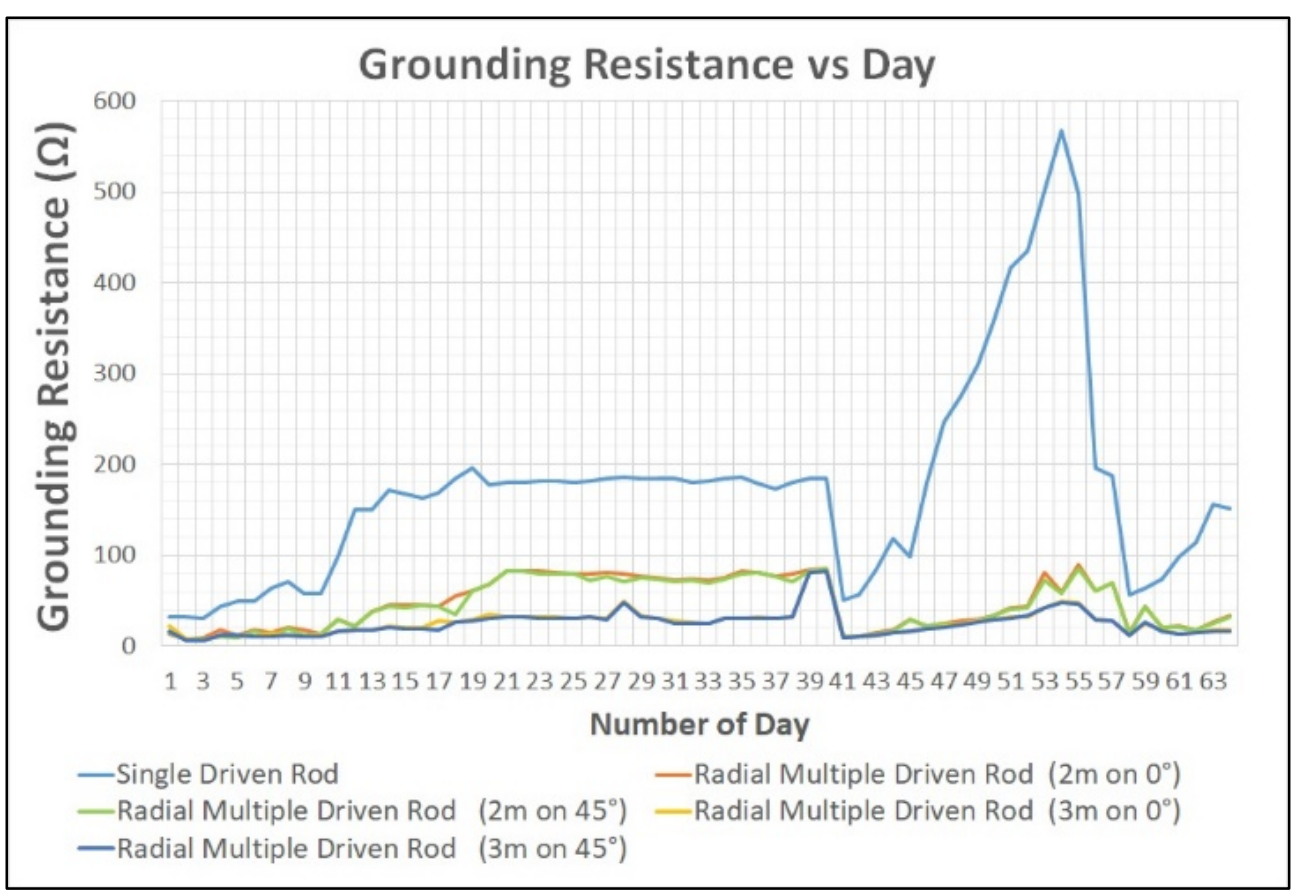

Figure 8. Grounding resistance of coconut husk grounding pit

Figure 8 illustrates the performance of grounding pit with coconut husk as additive material. With comparison to the Bentonite grounding pit, the resistance of all topologies was higher on beginning time but the slowly increase. In this grounding pit, the single driven rod shows the drastically changing either increase or decrease compared to the other topologies. All topologies increased mostly beyond day 11 and remained with not much changing onward before decreasing rapidly on day 41 . The trends resistance after that seems like previous until day 64 . The highest reached on day 54 with resistance of single driven rod being $567 \Omega$ while the lowest recorded with the resistance of $6.7 \Omega$ also on radial multiple driven rod with 3 $\mathrm{m}$ spacing distance between reference and outer electrodes. 
Table 3. Statistical Analysis of Additive Materials

\begin{tabular}{|c|c|c|c|c|c|c|c|c|c|c|c|}
\hline \multicolumn{6}{|c|}{ Bentonite } & \multicolumn{6}{|c|}{ Coconut Husk } \\
\hline & \multirow{2}{*}{$\begin{array}{c}\text { Single } \\
\text { Driven } \\
\text { Rod }\end{array}$} & \multicolumn{4}{|c|}{ Radial Multiple Driven Rod Topology } & & \multirow{2}{*}{$\begin{array}{c}\text { Single } \\
\text { Driven } \\
\text { Rod }\end{array}$} & \multicolumn{4}{|c|}{ Radial Multiple Driven Rod Topology } \\
\hline & & $\begin{array}{c}2 \mathrm{~m} \text { on } \\
0^{\circ} \\
(\Omega)\end{array}$ & $\begin{array}{c}2 \mathrm{~m} \text { on } \\
45^{\circ} \\
(\Omega)\end{array}$ & $\begin{array}{c}3 \mathrm{~m} \text { on } \\
0^{\circ} \\
(\Omega)\end{array}$ & $\begin{array}{c}3 \mathrm{~m} \text { on } \\
45^{\circ} \\
(\Omega)\end{array}$ & & & $\begin{array}{c}2 \mathrm{~m} \text { on } \\
0^{\circ} \\
(\Omega)\end{array}$ & $\begin{array}{c}2 \mathrm{~m} \text { on } \\
45^{\circ} \\
(\Omega)\end{array}$ & $\begin{array}{c}3 \mathrm{~m} \text { on } \\
0^{\circ} \\
(\Omega) \\
\end{array}$ & $\begin{array}{c}3 \mathrm{~m} \text { on } 45^{\circ} \\
(\Omega)\end{array}$ \\
\hline Min & 26.30 & 8.30 & 8.20 & 6.50 & 6.40 & Min & 31.10 & 8.20 & 7.90 & 6.80 & 6.70 \\
\hline Med. & 51.80 & 23.20 & 22.40 & 16.60 & 15.50 & Med. & 180.00 & 43.80 & 42.70 & 26.10 & 25.10 \\
\hline Max & 162.20 & 64.50 & 61.40 & 50.00 & 45.00 & Max & 567.00 & 89.00 & 84.90 & 82.70 & 82.30 \\
\hline Avg. & 54.76 & 25.39 & 24.45 & 19.55 & 18.40 & Avg. & 174.98 & 47.77 & 45.89 & 25.89 & 25.06 \\
\hline $\begin{array}{l}\text { Std. } \\
\text { Dev. }\end{array}$ & 27.73 & 11.64 & 11.59 & 9.14 & 8.51 & $\begin{array}{l}\text { Std. } \\
\text { Dev. }\end{array}$ & 114.17 & 27.60 & 27.02 & 14.21 & 14.20 \\
\hline
\end{tabular}

Statistical analysis is the method that can be interpreted and collection of samples data. The analysis is representing descriptive statistics which are to describe the sample that summarizes the population of data. Some information is taken in this analysis such as minimum and maximum of data, mean, average of data and standard deviation. Table 3 presented statistical analysis of both bentonite and coconut husk grounding pit. Regarding to the analysis found that single driven rod gives the highest value of standard deviation and the radial multiple driven rod star topology comes out with the lowest standard deviation.

\section{Conclusions}

From this experiment, it can be concluded that bentonite is the best additive material due to its lowest resistance compared to coconut husk. The reason is contributed by the properties of bentonite which is more stable in term of density, compactness, ability in water absorbing and resistivity of the material itself. Based on the electrodes arrangement topologies, the radial multiple driven rod is better than conventional single driven rod because more conductor will reduce the total resistance then reducing the current. The additional spacing of electrode also contributes to reducing resistance due to the decreasing of potential between them.

\section{Acknowledgements}

Authors would like to thank School of Electrical Systems Engineering, Universiti Malaysia Perlis on providing facilities and fund to complete this research.

\section{REFERENCES}

[1] R. B. Anderson, Eriksson A. J. Lightning parameters for engineering applications, CIGRE, Electra no 69, p. 65-102, 1980.
[2] C. Gomes. On the nature of lightning flashes: With special attention to the initiation, modeling, and remote sensing of return strokes, PhD Thesis, University of Colombo, 1999.

[3] C. Gomes, M. Z. A. Ab-Kadir, C. L. Kottachchi, S. C. Lim. Industrial Wastes and Natural Substances for Improving Electrical Earthing Systems, International Journal of Electrical Engineering, Vol.21, No.2, 39-47, 2014.

[4] Edvard, "3 good ways to improve earth electrode resistance" [Online]. Available: https://electrical-engineering-portal.co $\mathrm{m} /$ improve-earth-electrode-resistance [Retrieved on 25 November 2016].

[5] W. F. H. Wan Ahmad, N. H. Hamzah, J. Jasni, M. Z. A. Ab-Kadir, C. Gomes. A Study on Bentonite and Kenaf Properties for Grounding Purposes, International Conference on Lightning Protection, Rzeszow, Poland, 18, 2018.

[6] HazrekHamzah. Study on Grounding Grid Performance using Copper and Galvanized Steel, Bachelor of Engineering (Electrical) Final Year Project Report, UniversitiTeknologi Malaysia, Skudai, Johor, Malaysia, 2009.

[7] Copper vs. Galvanised-steel Grounding Rods, 2014. [Online]. Available: https://www.finishing.com/ 328/61.shtml. [Accessed: 23-Oct-2017].

[8] N. H. Halim, M. Z. A. Hasan, S. N. M. Arshad, M. Isa, A. Z. Abdullah, A. Anuar. Performance of Galvanized Steel and Copper Grounding Electrodes using Paddy Husk Ash as an Additive Material to Grounding System, International Conference on Power and Energy, Kuala Lumpur, Malaysia, 283-287, 2018.

[9] N. H. Halim, N. S. Jusoh, S. N. M. Arshad, M. Isa, A. Z. Abdullah, M. A. M. Isa. Analysis on Heat Transfer Distribution of Grounding System Using Finite Element Method, International Conference on Power and Energy, Kuala Lumpur, Malaysia, 257-262, 2018.

[10] S. N. M. Arshad, N. S. Tajudin, N. H. Halim, A. Z. Abdullah, C. L. Wooi, NurizianiHussin. Simulation on Lightning Effects to $132 \mathrm{kV}$ Underground Cable by Using Alternative Transients Program/Electromagnetic Transients Program (ATP/EMTP), International Conference on Power and Energy, Kuala Lumpur, Malaysia, 209-214, 2018.

[11] S. N. M. Arshad, M. N. A. A. M. Isnin, N. H. Halim, A. Z. Abdullah, C. L. Wooi, NurizianiHusin. Modeling and Analysis of Direct Lightning Strike to the Human Body, 
International Conference on Power and Energy, Kuala Lumpur, Malaysia, 184-189, 2018.

[12] N. H. Halim, A. Azfmi, Y. Yahya, F. Abdullah, M. Othman, M. S. Laili, Development of a Small Scale Standard Lightning Impulse Current Generator, International Power Engineering and Optimization Conference, Kuala Lumpur, Malaysia, 426-431, 2011. 